\title{
THORAX
}

Editorials

\section{The management of tuberculous meningitis}

Tuberculous meningitis is a life threatening form of tuberculosis and the most common form of central nervous system tuberculosis. The condition is a serious cause of morbidity and mortality in developing nations, but is rare in technically advanced countries. This probably reflects the global epidemiology of tuberculosis, for out of an estimated 8 million new cases annually 7.6 million $(95 \%)$ occur in the third world. ${ }^{1}$ In England and Wales in 1983 the rate of tuberculous meningitis for white patients was $0 \cdot 1 /$ 100000 , yet was 40 times higher (a rate of 4/100 000) in patients of Indian subcontinent ethnic origin. ${ }^{2}$ The total number of cases notified in England and Wales has remained below 100 since 1982 ; there were 81 notifications in 1990 (JM Watson and K Fern, personal communication), predominantly in adults.

Tuberculosis has emerged as an important clinical problem in patients with AIDS and its related complex, ${ }^{34}$ and extrapulmonary disease is particularly common. Central nervous system tuberculosis is an important manifestation. In one review of 420 patients in the United States with AIDS or the AIDS related complex 52 developed tuberculosis, 10 having the central nervous system affected, a rate of more than 2000 per $100000 . .^{5}$ In a population of HIV infected patients reported from Europe Mycobacterium tuberculosis was the most common cause of meningitis, with a frequency higher than that of Cryptococcus or other organisms. ${ }^{6}$ Clearly, patients with AIDS or the AIDS related complex have a substantially increased risk of developing tuberculosis of the central nervous system, and hence a review of appropriate management is timely.

The clinical importance of tuberculous meningitis is disproportionate to its rarity. Patients may spend months in hospital and there is an appreciable risk of irreversible neurological damage, including paralysis, mental retardation, epilepsy, and involuntary movements. Some may require institutional care. Hence the prompt recognition and treatment of tuberculous meningitis are important clinical considerations.

Whereas treatment of pulmonary tuberculosis is based on numerous extensive and well conducted controlled clinical trials, ${ }^{78}$ no substantial comparative studies have ever been conducted in tuberculous meningitis. Treatment is largely empirical; larger dosages of antituberculosis agents are often prescribed in the hope of overcoming the blood-brain barrier; and the optimum duration of treatment is unknown. Although this is unsatisfactory, appropriate guidelines for treatment can be suggested on the basis of relatively recent evidence on the penetration of antituberculosis drugs in the cerebrospinal fluid. The management of a patient with tuberculous meningitis includes properly supervised antituberculosis chemotherapy, judicious use of corticosteroids, and careful surveillance of clinical progress. Computed tomography and neurosurgical consultation are also important features of management.

\section{Factors influencing prognosis}

Tuberculous meningitis was first described as a separate entity in 1836 by Dr P H Green, while working at the Hôpital des Enfants Malades in Paris. ${ }^{9}{ }^{10}$ Green correlated clinical findings with meticulous pathological observations to define the illness; he associated granulations and tubercular infiltration of the pia with the occurrence of hydrocephalus and drew an analogy with tuberculous peritonitis: "Tubercular peritonitis has long been admitted into the science. The time, we believe, is not far off, when the term 'tubercular meningitis' will assume a rank by its side." The condition was recognised as being invariably fatal and the prognosis remained unchanged for more than 100 years after Green's publication. The discovery of streptomycin and the studies of the Medical Research Council, which started in 1946, showed that streptomycin could prolong life and, at least temporarily, restore health in some patients with tuberculous meningitis. " Important features emerged. It was evident that in children under three years of age and in those with advanced disease the prognosis was substantially worse. In those with early disease, with no neurological deficit (stage 1), the mortality was $46 \%$, compared with $86 \%$ in those in coma (stage 3 ). For those patients with neurological deficit but not in coma (stage 2) the mortality was $66 \%$. Prognosis was improved by intrathecal administration of streptomycin in addition to intramuscular treatment. Despite the high mortality in patients with advanced disease, the advent of streptomycin was clearly "an outstanding advance." 11

The introduction of isoniazid further improved prognosis, reducing the mortality in one series from $75 \%$ with streptomycin alone to $30 \%$ with streptomycin plus isoniazid. ${ }^{12}$ Although streptomycin plus isoniazid dramatically improved prognosis, the influence of rifampicin and pyrazinamide on prognosis is less clear. In India the addition of pyrazinamide and rifampicin to streptomycin plus isoniazid did not appear to improve the outcome of treatment. ${ }^{1314}$ Thus the clinical stage at the start of treatment appeared more important than choice of regimen in determining survival.

The outcome in 199 children treated in Hong Kong between 1961 and 1984 was reviewed to examine potential prognostic factors; rifampicin had been introduced in 1970 and pyrazinamide in $1975 .{ }^{15}$ Of those presenting in stage 1 , $96 \%$ made a complete recovery, whereas the proportion with complete recovery declined to $78 \%$ in stage 2 and $21 \%$ in stage 3 (table 1). A multivariate analysis of patients' characteristics and chemotherapy regimens showed that only two statistically significant independent variables predicted prognosis-namely, stage at presentation $(\mathrm{p}<0.001)$ and age $(\mathrm{p}<0.001)$. Advanced stage at presentation andyounger age were associated with a poor prognosis, older children and those with milder disease being more "Tikely to have a favourable outcome. The introduction of rifampicin and pyrazinamide appeared not 
Table 1 Outcome by stage of disease at presentation

\begin{tabular}{|c|c|c|c|c|c|c|c|c|}
\hline \multirow{4}{*}{$\frac{\text { Stage }}{\text { Early (1) }}$} & \multirow{4}{*}{$\frac{\text { Total }}{49}$} & \multicolumn{6}{|c|}{ No (\%) of patients with } & \multirow{3}{*}{$\begin{array}{l}\text { No }(\%) \\
\text { who } \\
\text { died }\end{array}$} \\
\hline & & \multirow{2}{*}{\multicolumn{2}{|c|}{$\begin{array}{l}\text { Complete } \\
\text { recovery }\end{array}$}} & \multicolumn{4}{|c|}{ Functional disability } & \\
\hline & & & & Mil & & Moderate & Severe & \\
\hline & & 47 & $(96)$ & 1 & (2) & $1 \quad(2)$ & -- & -- \\
\hline Intermediate (2) & 78 & 61 & (78) & 7 & (9) & $6(8)$ & $3(4)$ & $1 \quad(1)$ \\
\hline Late (3) & 72 & 15 & (21) & 4 & (5) & $18(25)$ & $23(32)$ & $12(17)$ \\
\hline Total & 199 & 123 & $(62)$ & 12 & (6) & $25(13)$ & $26(13)$ & $13(6)$ \\
\hline
\end{tabular}

to have influenced the treatment outcome. These unexpected findings might be partially explained by recent data available from pharmacokinetic studies on cerebrospinal fluid.

Infection with HIV does not appear to alter the clinical manifestations or the prognosis of tuberculous meningitis, except that patients with CD4 counts below $0.2 \times 10^{9} / 1$ have a significantly reduced survival. ${ }^{6}$

\section{Medical treatment}

Successful treatment of tuberculous meningitis will depend to a great degree on the concentrations in the cerebrospinal fluid achieved by antituberculosis drugs. Information on the penetration of antituberculosis drugs into the cerebrospinal fluid was limited, however, until relatively recently. Earlier studies were often conducted on small numbers of patients, often with insensitive or unspecific methods (Ellard et al, in preparation).

Experimental studies indicated that meningeal permeability is increased by low protein binding, small molecular weight, non-ionisation of a drug, and high lipid solubility of the unionised moiety. ${ }^{16-18}$ High lipid solubility, however, though aiding passage through the blood-brain barrier, often results in high protein binding ${ }^{19}$ and consequently poorer penetration into the cerebrospinal fluid. But pathological changes such as meningitis may disrupt the normal integrity of the blood-brain barrier (clefts may appear between adjacent endothelial cells) and allow greater penetration into the cerebrospinal fluid. ${ }^{2021}$

The first streptomycin studies ${ }^{22}$ found negligible penetration of drugs into the cerebrospinal fluid unless the meninges were inflamed. Even then large parenteral dosages achieved cerebrospinal fluid concentrations only $20 \%$ of the simultaneous serum concentrations. In the Medical Research Council studies of streptomycin in tuberculous meningitis ${ }^{11}$ cerebrospinal fluid concentrations of streptomycin varied according to the severity of the disease. The concentrations were at first appreciable, but declined significantly when the patient started to improve and the integrity of the blood-brain barrier was restored. Much higher concentrations of streptomycin could, however, be achieved in the cerebrospinal fluid if the drug was given by intrathecal injection. Intrathecal treatment has now largely been abandoned since the introduction of drugs with appreciable penetration into the cerebrospinal fluid, and this practice has not adversely effected prognosis. ${ }^{15}$ Recent studies in Chinese patients have shown that daily doses of $750 \mathrm{mg}$ streptomycin gave cerebrospinal fluid levels only slightly in excess of the minimum inhibitory concentration (MIC) for $M$ tuberculosis ${ }^{23}$ (Ellard et al, in preparation).

By contrast, isoniazid, which is non-protein bound, rapidly penetrates into the cerebrospinal fluid, whether or not the meninges are inflamed, to give concentrations more than 30 times the MIC for $M$ tuberculosis. ${ }^{24-26}$

The importance of rifampicin in the treatment of pulmonary tuberculosis is well recognised. ${ }^{27}$ Its potential contribution to the treatment of tuberculous meningitis is, however, uncertain. Rifampicin is highly protein bound ${ }^{28}$ and only up to $20 \%$ (the non-protein bound fraction) is available to penetrate into the cerebrospinal fluid. Peak plasma concentrations are obtained at about 4 hours. ${ }^{29}$ Early reports indicated that rifampicin penetrates poorly into the cerebrospinal fluid. ${ }^{30-33}$ Thus cerebrospinal fluid concentrations range from only $2 \%$ to $10 \%$ of the concomitant plasma concentration at 4 hours. ${ }^{34}$ The cerebrospinal fluid:serum ratios of rifampicin have since been shown to increase with time from 0.03 at 2 hours to 0.05 at 5-6 hours and $0 \cdot 10$ at 8 hours in 12 Chinese patients with tuberculous meningitis. ${ }^{35}$ Concentrations of rifampicin in the cerebrospinal fluid were only marginally above the MIC, findings that have since been confirmed in other studies $^{36}$ (Ellard et al, in preparation). Further, two hour rifampicin concentrations showed a positive correlation with protein and a negative correlation with glucose in the cerebrospinal fluid and at 5 hours rifampicin concentrations correlated with high cerebrospinal fluid white cell count, suggesting that the penetration of rifampicin into the cerebrospinal fluid may be related to the degree of meningeal inflammation. ${ }^{35}$

The relatively low concentrations of rifampicin in the cerebrospinal fluid are likely to be similar to the concentrations found in cavity walls in pulmonary tuberculosis, a condition where the contribution of rifampicin has been shown to be critical for the success of short course regimens. Although the contribution of rifampicin is unproved, possibly rifampicin is almost as active in tuberculous meningitis as in pulmonary tuberculosis.

Pyrazinamide has a sterilising effect on tubercle bacilli in an acid environment, and its incorporation in short course chemotherapy for pulmonary tuberculosis has significantly reduced relapse rates. ${ }^{27}{ }^{37}$ Oral doses of the drug are rapidly absorbed and peak serum concentrations are achieved within two hours, being proportional to the dose given. ${ }^{38}$ It penetrates readily into the cerebrospinal fluid. Although evidence for this conclusion was for many years based on studies in a single patient, ${ }^{32}$ recently those results have been confirmed by several extensive studies. Thus a large study of 28 Chinese patients with tuberculous meningitis ${ }^{39}$ found cerebrospinal fluid:serum ratios of pyrazinamide of 0.74 , $1 \cdot 15$, and 1.09 at 2,5 , and 8 hours respectively after oral dosages of $34-41 \mathrm{mg} / \mathrm{kg}$. This excellent penetration was not influenced by the stage of disease, the presence or absence of active disease, the concomitant use of steroids, the duration of antituberculosis treatment, administration of either ethambutol or streptomycin, or the age or sex of the patient. These findings have been confirmed in reports from South Africa ${ }^{40}$ and Thailand. ${ }^{3641}$ These concentrations were above those required for the inhibition of growth of $M$ tuberculosis. ${ }^{42} 43$

The excellent cerebrospinal fluid penetration of pyrazinamide and its unique sterilising activity indicate the potential contribution of pyrazinamide in the treatment of tuberculous meningitis. Indeed, the Joint Tuberculosis Committee of the British Thoracic Society recommended that treatment regimens for tuberculous meningitis should include at least two months of pyrazinamide. ${ }^{44}$ Although early studies provided evidence of the clinical benefit of pyrazinamide, ${ }^{12}$ later studies have not confirmed these findings. ${ }^{1415}$

Ethambutol probably penetrates poorly into the cerebrospinal fluid except when the meninges are inflamed. ${ }^{45} 46$ In healthy adults doses of $50 \mathrm{mg} / \mathrm{kg}$ (twice the normal daily dose) did not produce measurable cerebrospinal fluid concentrations, although in patients with tuberculous meningitis significant concentrations could be detected three to four hours after an oral dose of 18.6-25 
$\mathrm{mg} / \mathrm{kg}^{47}$ These studies, however, used imprecise or unspecific methods (Ellard et al, in preparation) and so the accuracy of the data is questionable. Cerebrospinal fluid studies using the specific and sensitive gas-liquid chromatographic method of Lee et al $^{4849}$ have yet to be conducted.

There is good evidence that ethionamide crosses both healthy and inflamed meninges. After an oral dose the cerebrospinal fluid concentration of ethionamide rises to a peak at three hours (the serum peak is at one hour), and thereafter the cerebrospinal fluid and serum concentrations are similar. The peak cerebrospinal fluid concentrations of $1.0-2.6 \mu \mathrm{g} / \mathrm{ml}$ following a dose of $250 \mathrm{mg}$ are comparable to concentrations achieved in the serum. ${ }^{50}$ Higher doses $(20$ $\mathrm{mg} / \mathrm{kg}$ ) have been given to children to obtain cerebrospinal fluid concentrations consistently above the MIC for $M$ tuberculosis. ${ }^{51}$

\section{Role of corticosteroids}

The role of corticosteroids in tuberculous meningitis has been a source of debate and controversy over the years, having both enthusiastic proponents ${ }^{1252}$ and opponents. ${ }^{534}$ In theory, corticosteroids suppress the inflammatory response in tuberculous meningitis, reduce cerebral oedema, and inhibit the formation of fibrous tissue, preventing complications such as nerve palsies, hydrocephalus, and spinal block. Hydrocortisone and cortisone have been shown experimentally to inhibit the growth of fibroblasts in experimentally induced arachnoid lesions, hydrocortisone being particularly effective. ${ }^{52}$ Editorial comments, however, have ranged from "There is no place for the routine use of cortisone or its analogues in tuberculous meningitis" patients with tuberculous meningitis." 55 Others have indicated that their use should be reserved for special circumstances, such as cerebral oedema or spinal block. $^{525356}$ Intrathecal hydrocortisone is effective in preventing total spinal block in the presence of threatened or early spinal block. ${ }^{52}$

Whereas an informative comparative study has been carried out in tuberculous pericarditis, where the indications for corticosteroids are now clear, ${ }^{57}$ definitive prospective randomised studies have yet to be undertaken in tuberculous meningitis. Reduction of mortality by corticosteroids in the acute phase has, however, been reported, ${ }^{12}$ even though evidence for such benefit was often based on small numbers of patients. ${ }^{58-61}$

In a comprehensive review of published reports up to 1966 Horne $^{62}$ concluded that there was sufficient evidence to recommend their use in patients in clinical stage 3 , but no evidence of benefit in stage 1 . The evidence of benefit was equivocal for those in stage 2 , but on balance their use in this group was recommended. A large study from China, ${ }^{63}$ in which patients were allocated to receive or not receive corticosteroids, provided some evidence to support this view (table 2 ). There were no deaths in patients with stage 1 disease in the treated or control groups. Steroids reduced the mortality, however, in patients in stage 2 and 3 . There are no data on morbidity, and we do not know whether the decrease in mortality was at the expense of increased disability in the survivors. Furthermore, the actual numbers in the two groups suggest that allocation of patients to either group was not random. Nevertheless, in the light of a review of the published data the addition of corticosteroids to antituberculosis chemotherapy for patients with stage 2 or 3 disease is recommended.

\section{Neurosurgical surveillance and treatment}

The most important complications of tuberculous meningitis that require neurosurgical surveillance and possible intervention are hydrocephalus, tuberculoma, and, rarely, abscess formation. Neurosurgical advice is often helpful and early consultation is advisable. Computed tomography is valuable in both the diagnosis and the management of tuberculous meningitis. An early scan is advisable and further examinations are performed as indicated by clinical progress. Both hydrocephalus and tuberculoma may develop after initial improvement, and clinical deterioration is an indication for a further scan.

The management of hydrocephalus includes drainage by ventriculoatrial $^{67}$ or ventriculoperitoneal ${ }^{68}$ shunt. Hydrocephalus may be detected at presentation or may develop subsequently, often presenting as a deterioration in consciousness. Early drainage has been advised. ${ }^{68-70}$ Mortality appears to be related to the severity of hydrocephalus. ${ }^{70} 71$ In a study of 56 patients those who had the ventricles drained fared significantly better than those who did not. ${ }^{72}$

Moderate or severe hydrocephalus complicating tuberculous meningitis is often associated with raised intracranial pressure. This is not always the case, however; ventriculomegaly may also be a sign of cerebral atrophy secondary to tuberculosis infection or may indicate a stable condition of compensated hydrocephalus. ${ }^{73}$

Tuberculous meningitis may be complicated by tuberculoma formation, though tuberculoma may occur in the absence of meningitis. The lesions are usually intracerebral $^{74}$ and only rarely meningeal. ${ }^{75} 76$ They may appear or enlarge after the start of adequate chemotherapy, ${ }^{77-80}$ or may appear only transiently. ${ }^{81}$ In one patient an increase in size of the tuberculoma occurred during the time when corticosteroids were being reduced, with conversion of the tuberculin response to strongly positive and development of lymphocyte transformation in the presence of tubercutin. 82 The mechanism of tuberculoma formation or enlargement has therefore been postulated to be an immune reaction to mycobacterial cell wall components, which can be experimentally reproduced in the animal model.$^{83}$ Surgical intervention, however, is rarely required. In one series of 50 patients with intracranial tuberculoma only three $(6 \%)$ required surgical excision. ${ }^{84}$ Excision or debulking may be required if a vital structure, such as the optic pathway, is compromised. ${ }^{85}$ Clinical deterioration after detection of a tuberculoma may indicate enlargement of the lesion, development of cerebral oedema, or liquefaction with abscess formation. ${ }^{86}$ Drainage of pus may be required, particularly if large tuberculous abscesses develop. ${ }^{87}$

\section{Treatment recommendations}

It is important to remember that neither these nor other recommendation ${ }^{44}$ are based on evidence provided by randomised controlled clinical trials. Further factors that must also be considered in the treatment of individual patients are age, renal or hepatic disease, and pregnancy. Streptomycin should be omitted in pregnancy and in those with renal impairment, and the dosage reduced in the elderly. Pyrazinamide should be avoided in hepatic disease,

Table 2 Tuberculous meningitis in Chinese adults: effect of treatment with corticosteroids $\star$

\begin{tabular}{|c|c|c|c|c|}
\hline \multirow[b]{2}{*}{ Stage } & \multicolumn{2}{|l|}{ Steroids } & \multicolumn{2}{|c|}{ No steroids } \\
\hline & $\begin{array}{l}\text { No of } \\
\text { patients }\end{array}$ & $\begin{array}{l}\text { No (11/) of } \\
\text { deaths }\end{array}$ & $\begin{array}{l}\text { No of } \\
\text { patients }\end{array}$ & $\begin{array}{l}\text { No }(1 / 11) \text { of } \\
\text { deaths }\end{array}$ \\
\hline Early (1) & 33 & -- & 22 & -- \\
\hline Intermediate (2) & 206 & $10 \quad(5)$ & 61 & $7(12)$ \\
\hline Late (3) & 100 & $30(30)$ & 23 & $14(61)$ \\
\hline Totals & 339 & $40(12)$ & 106 & 21 \\
\hline
\end{tabular}

^Adapted from Shaw et al."3 
and possibly rifampicin also ${ }^{88}$ Current treatment regimens in Hong Kong are based on daily treatment with isoniazid, rifampicin, pyrazinamide, and streptomycin, because these form the most potent sterilising combination when used for the treatment of pulmonary tuberculosis. Four drugs are given because of the high level of isoniazid resistance in Asia. In populations with little isoniazid resistance, such as white patients in England and Wales, streptomycin can be omitted. Isoniazid is usually prescribed in doses of about 10 $\mathrm{mg} / \mathrm{kg}$. Rifampicin $(10 \mathrm{mg} / \mathrm{kg}$ ) is given, though the contribution of the relatively low cerebrospinal fluid concentrations is not clear. Rifampicin is important, however, for pulmonary or miliary disease, which may occur simultaneously in up to half of the patients with tuberculous meningitis. ${ }^{15}$ Cerebrospinal fluid concentrations of pyrazinamide have been reported in excess of its MIC for $M$ tuberculosis with $30-40 \mathrm{mg} / \mathrm{kg}$ doses ${ }^{359} ; 35 \mathrm{mg} / \mathrm{kg}$ would be a suitable dose for both adults and children. If the patient is comatose, drugs can be administered via a nasogastric tube, preferably on a empty stomach. Streptomycin $(20 \mathrm{mg} / \mathrm{kg})$, with a maximum dose of $1 \mathrm{~g}$ a day, is given for the first two months of treatment, when the meninges are inflamed and cerebrospinal fluid penetration is maximal.

When there is reason to suspect that a patient is infected with an isoniazid resistant strain, we also give ethionamide in a daily dose of $15 \mathrm{mg} / \mathrm{kg}$. Ethionamide penetrates into the cerebrospinal fluid and forms part of routine therapy in South Africa, where tuberculous meningitis is common and clinicians have considerable experience in its use, in preference to streptomycin..$^{89}$

The optimum duration of treatment of tuberculous meningitis is unknown. Longer treatment regimens are likely to have lower relapse rates; the costs may be higher, however, and the risks of toxicity or poor compliance are greater. ${ }^{90}$ There may be social problems associated with prolonged hospitalisation, in children as well as adults. Some authors, however, would favour treatment that is probably unnecessarily long rather than put the patient at risk of relapse..$^{56}$ Although durations of 18-24 months have been advocated, ${ }^{11}$ there is limited evidence that six to 12 months may suffice. ${ }^{92-94}$ In a study in Thai adults treated with daily streptomycin, isoniazid, rifampicin, and pyrazinamide for two months followed by daily isoniazid and rifampicin for seven months there were no recurrences in patients who completed treatment, though four patients failed to complete treatment owing to poor compliance. ${ }^{92}$ In Thai children treated for six months there were no relapses after 12 months' follow up, ${ }^{93}$ and in India the outcome of nine months' treatment was similar to that of longer regimens. ${ }^{94}$

The duration of treatment is often related to the initial severity of the illness, but there are no controlled clinical trials to support this practice. The evidence that prognosis is primarily related to clinical stage indicates that rapid initiation of effective chemotherapy is extremely important. A substantial proportion of cerebral damage may be irreversible, so the rationale for longer treatment of severe cases is questionable. In Hong Kong those in stages 1 and 2 are treated for 12 months, though nine months may be adequate. Patients in stage 3 are treated for at least 12 months and often for 18 months; patients with intracranial tuberculomas are treated for 18-24 months.

After the initial period in hospital daily supervised treatment is continued on an outpatient basis if possible. In contrast to studies on pulmonary tuberculosis, there are no data on the efficacy of thrice weekly regimens in meningitis.

Corticosteroids are prescribed routinely for patients in stages 2 and 3. Dexamethasone is given in a dose of $0 \cdot 2$ $\mathrm{mg} / \mathrm{kg}$ for one to three weeks initially, being tailed down to
$0.1 \mathrm{mg} / \mathrm{kg}$ and continued for a total of two to three months, depending on clinical progress.

Crucial to the successful management of tuberculous meningitis are prompt diagnosis and commencement of antituberculosis chemotherapy. Because of the protean clinical presentations there is an ever present risk of overlooking or delaying the diagnosis..$^{95}$ As one experienced author has said, "Delay through bewilderment or procrastination through uncertainty is dangerous and often leads to a worse prognosis." 96

MICHAEL HUMPHRIES Roche Asian Research Foundation PO Box 98595 East Post Office, Tsim Sha Tsui East Post Office,
Hong Kong

Reprint requests to: Dr M Humphries

1 Kochi A. The global tuberculosis situation and the new control strategy of the World Health Organisation. Tubercle 1991;72:1-6.

2 Medical Research Council. National survey of notifications of tuberculosis in England and Wales in 1983: characteristics of disease. Tubercle 1987, 68:19-32.

3 Harries AD. Tuberculosis and human immunodeficiency virus infection in developing countries. Lancet 1990;i:387-90.

4 Watson JM, Gill ON. HIV infection and tuberculosis. BMJ 1990;300:63-5.

5 Bishburg E, Sunderam G, Reichman LB, Kapila R. Central nervous system tuberculosis with the acquired immunodeficiency syndrome and its related complex. Ann Intern Med 1986;105:201-13.

6 Berenguer J, Moreno S, Laguna F, Vincente T, Adrados M, Ortega A, et al. Tuberculous meningitis in patients infected with human immunodeficiency virus. $N$ Engl $J$ Med 1992;326:668-72.

7 Fox W. The scope of the controlled clinical trial, illustrated by studies in pulmonary tuberculosis. Bull WHO 1971;45:559-72.

8 Girling DJ. The chemotherapy of tuberculosis. In: Ratledge C, Stanford J, Grange JM, eds. Biology of mycobacteria. Vol 3. London: Academic Press, 1989:285-323.

9 Green PH. Observation on the tubercular meningitis of children with preliminary remarks on hydrocephalus. Lancet 1836:ii:263-76.

10 Green PH. Tubercular meningitis. Lancet 1836:ii:232-5.

11 Medical Research Council. Streptomycin in tuberculosis trials committee. Streptomycin treatment of tuberculous meningitis. Lancet 1948:i:582-97.

12 Wasz-Hockert O. Late prognosis in tuberculous meningitis. Acta Paediat 1962;51 (suppl 141):1-119.

13 Ramachandran P, Duraipandian M, Nagarajan M, Prabhaker R, Ramakrishnan CV, Tripathy SP. Three chemotherapy studies of tuberculous meningitis in children. Tubercle 1986;67:17-29.

14 Ramachandran P, Duraipandian M, Reetha AM, Mahalakshmi SM, Prabhaker $\mathbf{R}$. Long-term status of children treated for tuberculous meningitis in South India. Tubercle 1989;70:235-9.

15 Humphries MJ, Teoh R, Lau J, Gabriel M. Factors of prognostic significance in Chinese children with tuberculous meningitis. Tubercle 1990;71:161-8.

16 Brodie BB, Kurze H, Schankar LS. The importance of dissociation constant and lipid solubility in influencing the passage of drugs into the cerebrospinal fluid. J Pharmacol Exp Ther 1960;130:20-5.

17 Barling RWA, Selkon JB. Penetration of antibiotics into cerebrospinal fluid and brain tissue. $J$ Antimicrob Chemother 1978;4:203-27.

18 Schanker LS. Passage of drugs into and out of the central nervous system. Antimicrobial agents and chemotherapy. Washington DC: American Society for Microbiology, 1965:1044-50.

19 Young RC, Mitchell RD, Brown TH, Ganellin CR, Griffiths R, Jones M et al. Development of a new physicochemical model for brain penetration and its application to the design of centrally acting $\mathrm{H} 2$ receptor histamine antagonists. J Med Chem 1988;31:656-71.

20 Lithander A. Passage of penicillins into the cerebrospinal fluid and brain in experimental meningitis. Experimental investigations on rabbits. Postgrad Med J 1964;40 (supp):122-9.

21 Davson H. The blood-brain barrier. In: Bourne GH, ed. The structure and function of the nervous system. Vol 4. New York: Academic Press, 1972. 323-448.

22 Heilman DH, Heilman FR, Hinshaw HK, Nicholas DK, Herrel WE. Streptomycin: Absorption, diffusion, excretion and toxicity. $A m \mathrm{~J}$ Med Sci 1945;210:567-82.

23 Mitchison DA, Ellard GA. Antituberculosis drugs. In: Reeves DS, Philipps I, Williams JD, Wise R, eds. Laboratory methods in antimicrobial chemo therapy. Edinburgh: Churchill Livingstone, 1978:244-8.

24 Barclay WR, Ebert RH, LeRoy GV, Manthei RW, Roth LJ. Distribution and excretion of radioactive isoniazid in tuberculous patients. JAMA 1953;151:1384-8.

25 Elmdorf DF, Cawthorn WU, Muschenheim C, McDermott W. The absorption, distribution, excretion and short-term toxicity of isonicotinic acid hydrazide (Nyhydrazid) in man. Am Rev Tuberc 1952;65:429-42.

26 Fletcher AP. CSF-isoniazid levels in tuberculous meningitis. Lance 1953;ii:694-7.

27 Mitchison DA. Mechanism of drug action in short-course chemotherapy. Bull Int Union Tuberc Lung Dis 1985;60:34-7.

28 Bowman G, Ringberger UA. Binding of rifampicin by human plasma proteins. Eur J Clin Pharmacol 1974;7:369-73.

29 Ellard GA, Ellard DR, Allen BW, Girling DJ, Nunn AJ, Teo SK, et al. The bioavailability of isoniazid, rifampin and pyrazinamide in two commercially available combined formulations designed for use in the short-course treatment of tuberculosis. Am Rev Respir Dis 1986;133:1076-80.

30 Dippel JE, Mikhail IA, Girgis NI, Yousseff HH. Rifampicin concentration 
in cerebrospinal fluid in patients with tuberculous meningitis. Am $\operatorname{Rev}$ Respir Dis 1974;109:579-80.

31 D'Olivera JJ. Cerebrospinal fluid concentrations of rifampicin in meningeal tuberculosis. Am Rev Respir Dis 1972;106:432-7.

32 Forgan-Smith R, Ellard GA, Newton D, Mitchison DA. Pyrazinamide and other drugs in tuberculous meningitis. Lancet 1973:ii:374.

33 Larbaoui D, Boulahbal F, Ait-Khaled A, Baghbagha D, Benseman $H_{\text {, }}$ Bensafar SA. Étude des taux sériques et rachidiens de firampicine. Arch Inst Pasteur Alger 1973;51:171-81.

34 Stanley TV, Balakrishnan V. Rifampicin in neonatal ventriculitis. Aust Paediatr J 1982;18:200-1.

35 Woo J, Humphries MJ, Chan K, O'Mahoney G, Teoh R. Cerebrospinal fluid and serum levels of pyrazinamide and rifampicin in patients with tuberculous meningitis. Curr Ther Res 1987;42:235-42.

36 Kaojarern S, Supmonchai K, Phuapradit P, Mokkhavesa C, Krittiyanunt S. Effect of steroids on cerebrospinal fluid penetration of antituberculous drugs in tuberculous meningitis. Clin Pharmacol Ther 1991;49:6-12.

37 Girling DJ. The role of pyrazinamide in primary chemotherapy for pulmonary tuberculosis. Tubercle $1984 ; 65: 1-4$

38 Ellard GA. Absorption, metabolism and excretion of pyrazinamide in man Tubercle 1969;50:144-58.

39 Ellard GA, Humphries MJ, Gabriel M, Teoh R. The penetration of pyrazinamide into the cerebrospinal fluid in patients with tuberculous meningitis. $B M J$ 1987;294:284-5.

40 Donald PR, Seifart H. Cerebrospinal fluid pyrazinamide concentrations in children with tuberculous meningitis. Pediatr Infect Dis J 1988;7:469-71

41 Phuapradit P, Supmonchai K, Kaojarern S, Mokkhavesa C. The blood/ cerebrospinal fluid partitioning of pyrazinamide: a study during the course of treatment of tuberculous meningitis. J Neurol Neurosurg Psychiatry 1990;53:81-2.

42 Stottmeier KD, Beam RE, Kubika GP. Determination of drug susceptibility of mycobacteria to pyrazinamide in $\mathrm{H} 10$ agar. Am Rev Respir Dis 1967;96:1072-5.

43 Carlone NA, Acocella G, Cuffini AN, Forno-Pizzoglio M. Killing of macrophage-ingested mycobacteria by rifampicin, pyrazinamide, pyrazinoic acid alone and in combination. Am Rev Respir Dis 1985;132: $1274-7$.

44 Ormerod LP (for subcommittee of the Joint Tuberculosis Committee of the British Thoracic Society). Chemotherapy and management of tuberculosis in the United Kingdom: recommendations of the Joint Tuberculosis Committee of the British Thoracic Society. Thorax 1990;45:403-8.

45 Gundert-Remy U, Klett M, Weber E. Concentration of ethambutol in cerebrospinal fluid in man as a function of non-protein-bound fraction in serum. J Clin Pharmacol 1964;6:133-6.

46 Borrowitz ID. Ethambutol in tuberculous meningitis. Chest 1972;61:629-32.

47 Place VA, Pyle MM, de la Huerga J. Ethambutol in tuberculous meningitis. Am Rev Respir Dis 1969;99:783-5.

48 Lee CS, Gambertoglio TG, Brater DC, Benet LZ. Kinetics of oral ethambutol in the normal subject. Clin Pharmacol Ther 1977;22:615-21.

49 Lee CS, Brater DC, Gambertoglio JG, Benet LZ. Disposition kinetics of ethambutol in man. J Pharmacokinet Biopharmacol 1980;8:335-46.

50 Hughes IE, Smith HV, Kane PO. Ethionamide and its passage into the cerebrospinal fluid in man. Lancet 1962:i:616-7.

51 Donald PR, Seifart HI. Cerebrospinal fluid concentrations of ethionamide in children with tuberculous meningitis. J Pediatr 1989;115:483-6.

52 Lorber J. Treatment of tuberculous meningitis. BMJ 1960:i:1309-12.

53 Hockaday JM. Smith HV. Corticosteroids as an adjuvant to the chemotherapy of tuberculous meningitis. Tubercle 1966;47:75-91.

54 Smith H. Tuberculous meningitis. Int J Neurol 1964;4:134-57.

55 Allen MB, Cooke NJ. Corticosteroids and tuberculosis. BMJ 1991;303: 871-2.

56 Parsons $M$. The treatment of tuberculous meningitis. Tubercle 1989;70: 79-82.

57 Strang JIG, Kakaza HHS, Gibson DG, Allen BW, Mitchison DA, Evans DJ, et al. Controlled clinical trial of complete open surgical drainage and of prednisolone in treatm
Lancet $1988 ;$ ii:759-64.

58 Voljavec BF, Corpe RF. The influence of corticosteroid hormones in the treatment of tuberculous meningitis in negroes. Am Rev Respir Dis 1960;81:539-45.

59 Ashby M, Grant H. Tuberculous meningitis treated with cortisone. Lancet 1955;i:65-6.

$60 \mathrm{Kinsell} \mathrm{LW}$. The clinical application of pituitary adreno-corticotrophic and adrenal steroid hormones. Ann Intern Med 1951;35:615-8.

61 Escobar JA, Belsey MA, Duenas A Medina. Mortality from tuberculous meningitis reduced by steroid therapy. Pediatrics $1975 ; 56: 1051-5$.

62 Horne NW. A critical evaluation of corticosteroids in tuberculosis. Adv Tuberc Res 1966;15:1-54.

63 Shaw PP, Wang SM, Tung SG, Niu QW, Lu TS, Yu XC, et al. Clinical analyis of $\mathbf{4 4 5}$ adult cases of tuberculous meningitis. Chinese $J$ Tuberc Respir Dis 1984;3:131-2.
64 Bhargava S, Gupta AK, Tandon PN. Tuberculous meningitis-a CT study. Br J Radiol 1982;55(651):189-96.

65 Bullock MR, Welchman JM. Diagnostic and prognostic features of tuberculous meningitis on CT scanning. J Neurol Neurosurg Psychiatry 1982; 45:1098-101

66 Teoh R, Humphries MJ, Hoare RD, O'Mahoney G. Clinical correlation of CT changes in 64 Chinese patients with tuberculous meningitis. J Neurol 1989;236:48-51.

67 Murray HW, Brandstetter RD, Lavyne MH. Ventriculo-atrial shunting for hydrocephalus complicating tuberculous meningitis. Am J Med 1981; 70:895-8.

68 Roy TK, Sircar PK, Chandar V. Peritoneal-ventricular shunt in the management of tuberculous meningitis. Indian J Paediatr 1979;16: 1023-7.

69 Bullock MR, Van Dellen JR. The role of cerebrospinal fluid shunting in tuberculous meningitis. Surg Neurol 1982;18:274-7.

70 Palur R, Rajshekhar V, Chandy MJ, Joseph T, Abraham J. Shunt surgery for hydrocephalus in tuberculous meningitis: a long-term follow-up study. J Neurosurg 1991;74:64-9.

71 Arens LJ, Deeny JE, Molteno CD, Kibel MA. Tuberculous meningitis in children in the Western Cape: neurological sequelae. Paediatr Rev Comm 1977;1:257-75.

72 Peacock WJ, Deeny JE. Improving the outcome of tuberculous meningitis in childhood. S Afr Med J 1984;66:597-8.

73 Schoeman JF, Le Roux D, Bezuidenhout PB, Donald PR. Intracranial pressure monitoring in tuberculous meningitis: clinical and computerised tomographic correlation. Developmental Medicine and Child Neurology 1985;27:644-54.

74 Loizou LA, Anderson M. Intracranial tuberculomas; correlation of computerized tomography with clinico-pathological findings. $Q J \mathrm{Med} 1982$ 201:104-14.

75 Arrington JA. Meningeal tuberculoma. Semin Roentgenol 1987;22:7-8.

76 Chang CM, Chan FL, Yu YL, Huang CY, Woo E. Tuberculous meningiti associated with meningeal tuberculoma. J R Soc Med 1986;79:486-7.

77 Lees AJ, Macleod AF, Marshall J. Cerebral tuberculomas developing during treatment of tuberculous meningitis. Lancet 1980:i:1208-11.

78 Chambers ST, Hendrickse WA, Record C, Rudge P, Smith H. Paradoxica expansion of intracranial tuberculomas during chemotherapy. Lance 1984:ii:181-3

79 Hendrickse WA. Paradoxical expansion of intracranial tuberculomas during chemotherapy [letter]. Lancet 1984:ii:749-50.

80 Teoh. R, Humphries MJ, O'Mahoney G. Symptomatic intracranial tuberculoma developing during treatment of tuberculosis: a report of 10 patients and review of the literature. $Q J M e d$ 1987;241:449-60

81 Shepard WE, Field ML, James DH Jr, Tonkin IL. Tansient appearance of intracranial tuberculoma during treatment of tuberculous meningitis. Pediatr Infect Dis 1986;5:599-601.

82 Bouchez B, Arnott G. Paradoxical expansion of intracranial tuberculomas during chemotherapy. Lancet 1984:ii:470-1.

83 Colover J. Paradoxical expansion of intracranial tuberculomas during chemotherapy [letter]. Lancet 1984:ii:471.

84 Tandon PN, Bhargava S. Effect of medical treatment on intracranial tuberculoma - a CT study. Tubercle 1985;66:85-97.

85 Teoh R, Poon W, Humphries MJ, O'Mahoney G. Suprasellar tuberculoma developing during treatment of tuberculous meningitis requiring urgen surgical decompression. J Neurol 1988;235:321-2.

86 Clezy JKA. Paradoxical expansion of intracranial tuberculomas during chemotherapy [letter]. Lancet 1984:ii:750.

87 Tang ESC, Chau A, Fong D, Humphries MJ. The treatment of multiple intracranial tuberculous abscesses: a case report. J Neurol 1991;238:183-5.

88 Girling DJ. Adverse effects of antituberculous drugs. Bull Int Union Tuberc Lung Dis 1984;59:157-62.

89 Donald PR, Schoeman JF, O'Kennedy A. Hepatic toxicity during chemotherapy for severe tuberculous meningitis. Am J Dis Child 1987;141: 741-3.

90 Fox W. Compliance of patients and physicians: experience and lessons from tuberculosis. Parts 1 and 2. BMJ 1983;287:33-5, 101-5.

91 Juel-Jensen BE, Phuapradit P, Warrell DA. Bacterial meningitis. In: Wetherall DJ, Ledingham JGC, Warrell DA, eds. Oxford textbook of medicine. Vol 2. 2nd ed. Oxford: Oxford University Press, 1987:137-41.

92 Phuapradit $P$, Vejiajiva A. Treatment of tuberculous meningitis: role of short-course chemotherapy. $Q J$ Med 1987;239:249-58.

93 Sunakorn P, Pongparit S, Wongrun S. Short course chemotherapy in tuberculous meningitis: a pilot trial. Journal of the Medical Association of Thailand 1980;63:340-5.

94 Acharya VN, Kudva BT, Retnam VJ, Mehta PJ. Adult tuberculous meningitis: comparative study of different chemotherapeutic regimens. Journal of the Association of Physicians of India 1985;33:583-5.

95 Horne NW. Problems of tuberculosis in decline [editorial]. BMJ 1984; 288:1249-51.

96 Kennedy DM. Tuberculous meningitis [letter]. Lancet 1981:ii:261. 